\title{
Anatomy of an MBA Program Capstone Project Assessment Measure for AACSB Accreditation
}

\author{
Deborah M. Gray ${ }^{1}$, Vigdis Boasson ${ }^{1}$, Michael Carson ${ }^{1} \&$ Debasish Chakraborty ${ }^{1}$ \\ ${ }^{1}$ Central Michigan University, Mt. Pleasant, MI, USA \\ Correspondence: Dr. Deborah M. Gray, Professor of Marketing \& Interim Director of the MBA Program, College of \\ Business Administration, Central Michigan University, Smith 100, Mt. Pleasant, MI 48859, USA. E-mail: \\ chubb1dm@cmich.edu
}

Received: November 16, 2014

Accepted: December 8, 2014 Online Published: December 17, 2014

doi:10.5430/ijba.v6n1p1

URL: http://dx.doi.org/10.5430/ijba.v6n1p1

\begin{abstract}
There is very little written about assessment measures business schools use for assessing their programs that not only helps them meet the assessment criteria necessary for AACSB accreditation but also helps them improve the curriculum to build top-tier successful programs. This paper informs the literature on the assessment measure (and process) used by an MBA program to assess student learning through end-of-program capstone projects; success that is demonstrated by stabilized enrollments and a recent top-tier ranking. This paper is useful to any graduate or undergraduate business program that chooses to use capstone projects as an assessment measure to earn or renew AACSB accreditation. Following guidelines suggested by Banta $(2004,2007,2011)$ and Polomba and Banta, (1999) a defined process is implemented to collect, assess, and disseminate assessment data to improve the MBA curriculum.
\end{abstract}

Keywords: assessment, AACSB accreditation, assessment measures for AACSB accreditation, capstone projects

\section{Introduction}

Business school accreditation is a way for business schools to differentiate their brand and demonstrate "...the highest standard of achievement," (AACSB, 2014). To earn accreditation from the Association to Advance Collegiate Schools of Business (AACSB) a business school must demonstrate that they have met standards in four broad categories including how the school is managed (Standards 1-3), how the schools participants contribute to the learning environment (Standards 4-7), learning and teaching (Standards 8-12), and academic and professional engagement (Standards 13-15) (AASCB, 2013). This paper will focus on Standard 8, Assurance of Learning; specifically, the use of student projects for assessment of the MBA program at a top- 80 ranked university.

This paper seeks to expand the literature on the use, analysis, and implementation of MBA projects as a means of improving the program and fulfilling the requirements for Assurance of Learning for the purposes of earning AACSB accreditation. While there are studies that inform the literature on business schools' use of multiple choice questions (Santos, Aidong, \& Douglas, 2014), individual course analysis (Christiansen, Judd, \& Nicols, 2011), and course embedded direct assessment (LaFleur, Babin, \& Lopez, 2009), there is no peer-reviewed research that assists business colleges in understanding how to use student projects as an AACSB Assurance of Learning (AOL) measure. Pringle and Michal (2010) suggest that most business schools use test items or written deliverables embedded in class assignments. Specific examples of what test items or written deliverable are used and how they are used will reduce the need to 'reinvent the wheel' in assessment activities. This paper can also be useful to undergraduate programs that use projects as a means of assessing a specific program. This paper is not meant to debate the assessment process defined by AACSB but instead will inform the literature in modeling an assessment process that has undergone two successful iterations of AACSB accreditation and resulted in "Closing the Loop (CTL)" procedures that have boosted enrollments, and led to a ranked program.

We accomplish the objective of the paper by first addressing the importance of AACSB accreditation in a competitive higher education marketplace. We follow with a summary of the Assurance of Learning process as defined by AACSB and how this process informs the type of assessment measurement choices that university programs face. We follow with an MBA AOL assessment model that has undergone two successful accreditation iterations and resulted in programmatic changes that led the MBA program becoming nationally ranked. 


\section{Association to Advance Collegiate Schools of Business (AACSB)}

AACSB will celebrate 100 years of service to business schools in a few short years. AACSB's beginnings in 1916 are rooted in bringing U.S. business school faculty together to discuss issues related to teaching business; today AACSB is an international organization that has a membership of 681 business schools across 50 different countries and territories (AACSB, 2013). While AACSB accreditation is fairly well known in the United States it has only become more prominent in the international arena in the last ten years. Currently fewer than $5 \%$ of the 13,000-business schools worldwide have earned AACSB accreditation (AACSB, 2013). Business schools that earn AACSB accreditation must undergo a continuous improvement review every five years. For this reason assessment and AASCB AOL will continue to be of interest to business schools across the world.

\subsection{Assurance of Learning at the Program Level}

Assurance of Learning is a critical component of the AACSB accreditation process because it is the standard that documents that degree program goals have been met. Palomba and Banta (1999) define the outcomes assessment process as, "The systematic collection, review, and use of information about educational programs, undertaken for the purpose of improving student learning and development." AACSB relies heavily on the work of Palomba and Banta (1999) in training faculty on how to define and measure AOL (AACSB, 2013). AACSB Standard 8 suggests, "The school uses well-documented, systematic, processes for determinining and revising degree program learning goals; designing, delivering, and improving degree program curricula to achieve learning goals; and demonstrating that degree programs learning goals have been met." A critical building block to understanding AOL is that the focus is on programs not on individual classes.

AACSB does not mandate how colleges collect the data or what data is used and this both an advantage and disadvantage for colleges undergoing accredidation or reaccredidation. In other words there is no panacea for business school assessment; no standardized test that fits the many varied programs. To this end AACSB has expanded the dialog on the word 'program' so that business schools focus on broad-based content and not on classes, concentrations, or majors (AACSB, 2013). An AACSB white paper (2013) explains that curricular content should drive learning goals and that curricula shared a common core are justified in assessing that content as a 'program' ( $\mathrm{p}$. $6)$.

\subsection{The AACSB Assurance of Learning Model}

The AACSB assurance of learning model is a 5-step process that is based on the work of Palomba and Banta (1999):

1. Define student learning goals and objectives

2. Align the curricula with the goals

3. Identify assessment measures

4. Collect, analyze, and disseminate results and,

5. Close the loop

In this paper, we focus on steps 3-5 with emphasis on use of the capstone project as an assessment measure.

\subsubsection{Identifiying a Measure: Formative versus Summative Assessment Measures}

There are various approaches to assure student learning; however, AACSB (2003) suggests three approaches to assuring student learning including student selection, course-embedded measures, and stand-alone testing or performance. The first approach proposes that schools select students into a program based on the knowledge and skills they have already obtained previously and that support requirements of knowledge and skills for submission into the program. However, it is important to assess levels of student learning at the beginning of the program even after they meet the initial criteria standards. This type of initial assessment conducted at the beginning and midway through the program is known as formative assessment. This type of assessment is critical to establishing a foundation of analysis to truly measure advancements in learning (Suskie, 2009). Examples of formative assessment may include such instruments as observations of performance, assignments, short tests or quizzes, written questions, peer/self-evaluations, or projects. Though formative assessment practices are critical to further understand student learning in accredited programs, it is essential to recognize summative assessment practices in order to gain a holistic sense of what students have learned upon completion of the program (Suskie, 2009). Stand-alone testing or performance measures such as graduate exit exams and capstone projects provide an ideal opportunity to gather summative data on student learning. According to Palomba and Banta (2001), these assessment measures are idea for summative assessment since they can cover university-wide general outcomes as well as program specific outcomes 
such as an MBA program. For the purpose of this discussion, we will focus on end of program projects like the capstone project. The intention of these summative assessments are to provide stakeholders such as faculty and administrators with a snap shot of student learning as a result of a culminating course experiences within the programs. Instead of a single writing project or oral presentation that may be covered in a specific course, these assessments yield areas within the curriculum where students are either flourishing or struggling within a program.

\subsubsection{Collecting, Analyzing and Using the Data}

The data collection process for course embedded assignments may be carried out through such assessment instruments as case studies where students provide evidence of their ability to integrate, transfer, and apply learning they have recently acquired. In some instances, faculty may choose to use rubrics to score levels of learning and in other instances faculty may prefer to employ outside evaluators to analyze and score the assignments (Maki, 2010). Similarly, faculty may choose to use more elaborate means of data collection such as videotaping or observations to identify emerging abilities students have learned within the courses. Stand-alone projects such as an end of program capstone project may be more robust than course-embedded assignments where faculty have the option of collecting data on the students chronological learning (Maki, 2010). Furthermore, these types of assessment approaches also allow for student self-reflection that can be captured in written reports supported by artifacts acquired throughout the program.

Depending on the data collected, results may be analyzed in various ways. For instance, qualitative data may be analyzed by using themes, patterns, links and relationships among the results (Suskie, 2009). Categorical data such as responses to multiple choice questions can be tallied; however, it is difficult to provide means and medians (Suskie, 2009). This type of analysis may be used only to explore and predict learning levels. Ordered results such as those used in surveys and rubrics provide statistical analysis. According to Suskie (2009), explanations and predictions can be extrapolated from such analysis but programs must determine from the beginning what questions they are trying to answer. Assessments are often used to describe student learning; however, determining how results will be analyzed provides further insight into the intentions of assessment such as using results to explain, predict, or explore areas or levels of learning.

\subsubsection{Dissemination of the Results \& Closing the Loop}

All too often assessment results that are briefly pursued and filed away are many times considered a waste of time for faculty (Suskie, 2009). Using results to inform decisions can be one of the most difficult tasks in the whole assessment process but can yield valuable information to make evidence-based decisions. Some serious questions should be posed from faculty as a result of the assessment findings. For instance, faculty may ask why did certain groups of students do poorly on the assessment, is the assessment clearly addressing the learning goals, what decisions will be made as a result of the findings, is there a clear strategy in place to provide every student the opportunity to achieve the goals, are key concepts reinforced throughout the program (Suskie, 2009)? Pringle and Michael (2007) suggested that research should be conducted on how to reduce faculty resistance to assessment activities. Once faculty feels they have substantive evidence to address such questions, action plans should be formulated.

Action plans (closing the loop) may consist of key faculty members or groups of faculty exploring such areas as the curriculum. Suskie (2009) suggested that faculty consider such actions as possibly replacing a program elective with a required capstone course, have faculty review skills or key concepts over several courses, and reduce attention to less important goals to ensure greater coverage of more important goals. Maki (2010) suggested that decisions should lead to agreed upon time tables and activities involving faculty and staff that emerge from reflections and discussions of the results. These activities should include changes that once implemented lead to improved student learning. A timetable to reassess the implications of the changes on student learning is essential for quality assessment processes (Maki, 2010). Action planning is the key element to closing the loop - using data obtained by measuring student learning to plan, complete, and deploy improvements in educational programs and to reassess learning after improvements are made (Hersh, \& Keeling, 2013).

\section{Anatomy of a Successful AACSB Assurance of Learning Model}

Exhibit 1 shows the successful assurance of learning model used for an MBA program for a top 200 ranked university and a top ranked online MBA program. How is success defined? Our program defined success in terms of three outcomes: two successful iterations of renewel of AASCB accreditation, a curriculum revision that was based on results from the implemented assurance of learning model, and two years of recognition as a top-ranked online MBA program. 


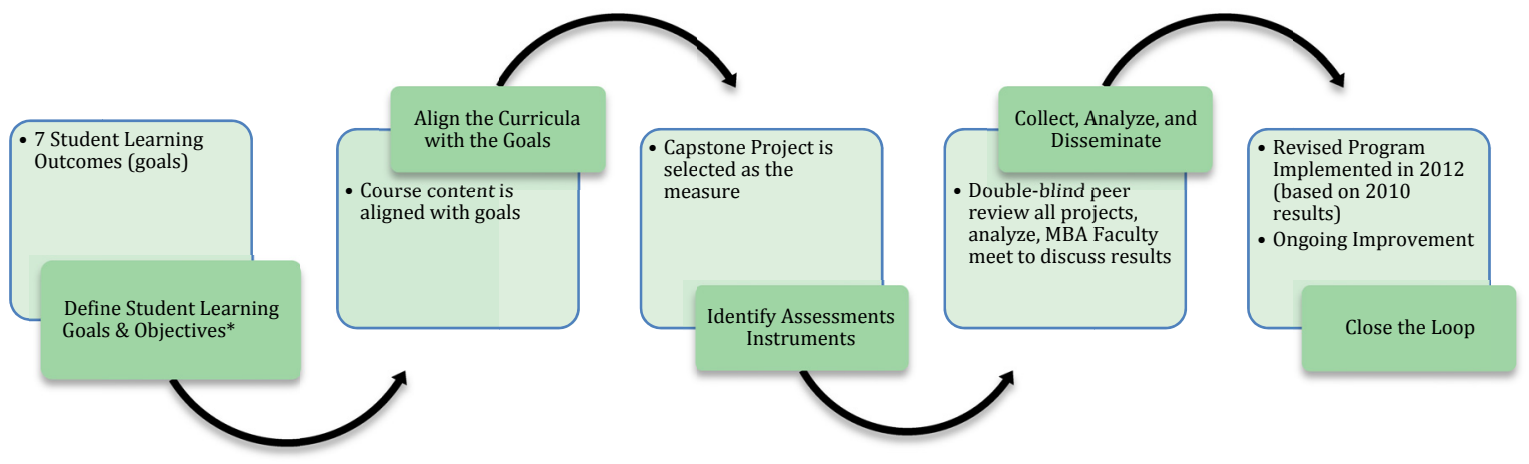

Exhibit 1. Anadomy of assurance of learning at a mid-western university

Based on the work of Palomba \& Banta (1999)

Palomba \& Banta (1999) program has identified 7 student learning outcomes (SLOs) that are aligned with the curriculum (specific courses are in parenthesis).

\section{General knowledge skills:}

1. Demonstrate effective communication skills in both writing and oral presentations (MBA 650, 680, 690, and 699)

2. Demonstrate understanding of the importance of socially responsible behavior (environmental, sustainability and ethical) in business decision-making process. (MBA 660, 680, and 690)

\section{Management specific skills:}

3. Demonstrate a global perspective in business decision-making process. (All MBA courses)

4. Demonstrate ability to apply quantitative decision making techniques and information systems for business problem solving (MBA 610,640, 680 and 669)

5. Demonstrate ability to evaluate and monitor the performance of a firm's financial operations (MBA 620 and 670)

6. Demonstrate ability to apply organizational structure and behavior principles to maximize employee performance (MBA 630, and 610)

7. Demonstrate ability to integrate functional business areas in the strategic planning process (MBA 690, 650 and 699)

\section{The Capstone Project as an Assessment Measure}

Twenty randomly selected projects were independently evaluated by two MBA faculty members to rate competency in the seven student learning outcomes (SLOs). Care was taken to make certain that no faculty member rated the performance of a project that they also advised.

Table 1 and Table 2 present the results from the MBA project assessment (exactly as they appear in the AACSB assessment report). The 7 student learning outcomes were assessed using a 5-point scale: 5=excellent and 1=poor based on the each faculty member's review of the project. Each faculty member reported their results in an excel spreadsheet and results were analyzed in aggregate. Faculty members were compensated with a $\$ 500$ stipend for their time to reduce faculty resistance to participating in this assessment activity. 
Table 1. Summary statistics

\begin{tabular}{lrrrrrrrrr} 
Rubric & Mean & Median & St.Dev & Kurt & Skew & Min & Max & N \\
Communication skills & 4.3 & 4.5 & 0.86 & 1.14 & -1.21 & 2 & 5 & 20 \\
\hline Socially Responsible & 3.9 & 4 & 0.55 & 0.77 & -0.08 & 3 & 5 & 20 \\
\hline Global Perspective & 4.1 & 4 & 0.79 & -1.31 & -0.19 & 3 & 5 & 20 \\
\hline Quantitative Skills & 3.4 & 3.5 & 0.68 & -0.45 & -0.71 & 2 & 4 & 20 \\
\hline $\begin{array}{l}\text { Monitor Financial } \\
\text { Performance }\end{array}$ & & & & & & & & \\
Sensitivity to Human Resource & 4.8 & 4 & 0.79 & 1.12 & -0.95 & 2 & 5 & 20 \\
\hline Integrate functional Areas & 4.0 & 4 & 0.51 & 1.65 & -0.11 & 3 & 5 & 20 \\
\hline
\end{tabular}

Table 2. Assurance of learning: Using the MBA project for an assessment measure

\begin{tabular}{lrrrrr} 
Rubric & Excellent & Good & Adequate & Week & \multicolumn{2}{l}{ Poor } \\
\hline Communication skills & $50 \%$ & $35 \%$ & $10 \%$ & $5 \%$ & $0 \%$ \\
\hline Socially Responsible & $10 \%$ & $70 \%$ & $20 \%$ & $0 \%$ & $0 \%$ \\
\hline Global Perspective & $35 \%$ & $40 \%$ & $25 \%$ & $0 \%$ & $0 \%$ \\
\hline Quantitative Skills & $0 \%$ & $50 \%$ & $40 \%$ & $10 \%$ & $0 \%$ \\
\hline Monitor Financial Performance & $10 \%$ & $65 \%$ & $15 \%$ & $10 \%$ & $0 \%$ \\
\hline Sensitivity to Human Resource & $10 \%$ & $75 \%$ & $15 \%$ & $0 \%$ & $0 \%$ \\
\hline Integrate functional Areas & $35 \%$ & $55 \%$ & $10 \%$ & $0 \%$ & $0 \%$ \\
\hline
\end{tabular}

(Percentage of Students Achieving Learning Goals)

As shown in Table 1, the median scores for most of the SLOs are in 4 or better. Table 2 shows the percentage of students meeting and exceeding expectation. For instance, in terms of "Communication skills" most students do very well with a median of 4.5; $85 \%$ of students have reached "Good" or "Excellent" levels. In terms of "Socially Responsible" most students do well with a median score of 4 with $80 \%$ of students have reached "Good" or "Excellent" levels. In terms of "Global Perspective" the median score is 4.1 and $75 \%$ of students have reached "Good" or "Excellent" levels. Finally with regard to "Quantitative Skills" the median score is 3.5 respectively and $50 \%$ of students have reached "Good" level, $40 \%$ have reached "adequate" level, and $0 \%$ have reached "Excellent" level. The "Monitor Financial Performance" SLO data shows a median score of 4.0 and $75 \%$ of students have reached "Good" to "Excellent" levels. In terms of "Sensitivity to Human Resource", the median score is 4.0 and $85 \%$ of students have reached "Good" to "Excellent" levels. Lastly, the "Integrate Functional Areas" SLO data shows a median score of 4.0 and $90 \%$ of students have reached "Good" to "Excellent" levels.

The area that was identified for further analysis and improvement is the "Quantitative Skills" SLO.

\subsection{Dissemination of the Results}

MBA faculty are encouraged, but not required to attend a CTL meeting once per year; attendance is typically around $60 \%$. To encourage participation in this activity a number of strategies are used including: choosing a day of the week that the majority of faculty will be able to attend, sending out an agenda in advance of the meeting, keeping the meeting concise and as short as possible, providing lunch for attendees, and including the university assessment director so that he can provide guidance and expertise when necessary. Results are presented by providing a physical document that faculty can take with them for future reference; the packet includes current and historical data which aids in getting a 'big picture' of how current results compare to past results.

\subsection{Closing the Loop}

Faculty are asked for their input and ideas for improvement in areas that show little or no improvement from previous years. Faculty are encouraged to brain storm without regard to costs or feasibility. These ideas are recorded and discussed during by the Graduate Business Studies Committee which is the primary decision-making committee 
for the MBA program. The AOL process including declining measurement results in 2010 and 2011 led to a complete revision of the MBA progam including goals and curriculum. As a result of Closing the Loop-that is, making changes directly tied to student learning results, the program has increased from 36 to 39 credits and as a result, the program has stabilized enrollments and recently become ranked nationwide.

We use the MBA project assessment to close the loop for each of our student learning goal in our AOL system. For instance, Table 3 and Table 4 demonstrate our results in closing the loop for each of our SLO from 2011 to 2014.

Back in 2011 shortly after our MBA program revision, we conducted our program assessment using MBA capstone course projects. Results of 2011 project assessment show that our weakest area is the "Integrate Functional Business Areas" SLO which has a mean score of 2.88; $\%$ of students reached "Excellent" and less than $30 \%$ of students reached the "Good" level (see Table $3 \& 4$ ). According to Table 4 assessment results, after adding up the "Good" and "Excellent" categories of results for 2011, those SLO areas that need improvements are "Monitoring Financial Performance" (only $31 \%$ of students reaching "Good" or better), "Sensitivity to HR" (only $26 \%$ of students reaching "Good" or better), and "Integrate functional business areas" (only $31 \%$ of students reaching "Good" or better). Thus each faculty teaching MBA capstone courses has taken various improvement efforts in increase student learning in these key areas. By the year 2014, according to Table 3, our project assessment results show improvement on all SLOs except "quantitative skills". The most impressive improvement is with the "integrate functional business areas" SLO, a $47.5 \%$ increase in terms of mean scores. In terms of percentage of students reaching "good" or better for 2014 as shown in Table 4, we have seen improvements in all SLOs except "Quantitative Skills". The most impressive improvement areas from 2011 to 2014 are "Monitor financial performance" (142\% increase), "Sensitivity to HR" (225\% increase), and "Integrate functional business areas" (191\% increase), the same three areas we identified that need improvements back in 2011. However, our assessment results in terms of mean scores and percentage of students achieving "Good" or better in 2014 indicate that the area that needs further improvement is needed for the "quantitative skills" SLO. As a result of faculty discussions and reflections the program has decided to improvement our AOL system for this SLO by adopting the Bloomberg Aptitude Test (BAT) as a supplementary measurement for students' quantitative skills. BAT has also been adopted successfully in the undergraduate finance program assessment at this university.

Table 3. Closing the loop using MBA project for assessment 2011-2014

(Mean scores)

\begin{tabular}{|c|c|c|c|c|c|}
\hline SLOs & $2011-$ & $12=$ & $13=$ & $14 \div \% \mathrm{c}$ & $2 0 1 4 \longdiv { 7 }$ \\
\hline Communication Skills & 4.17 & 4.54 & 4.1 & 4.31 & $3.2 \%$ \\
\hline Socially Responsible & 3.60 & 3.89 & 3.7 & $3.9 \hat{1}$ & $8.5 \%$ \\
\hline Global Perspective & 3.57 & 3.46 & 3.8 & 4.11 & $14.8 \%$ \\
\hline Quantitative Skills & 3.57 & 4.14 & 3.85 & $3.4 \sqrt{2}$ & $-4.8 \%$ \\
\hline Monitor Financial Performanc & 3.10 & 3.64 & 3.65 & 3.751 & $21.2 \%$ \\
\hline Sensitivity to HR & 3.12 & 3.61 & 3.85 & 3.95 亿 & $26.6 \%$ \\
\hline Integrate Functional Areas & 2.88 & 3.25 & 3.9 & 4.251 & $47.5 \%$ \\
\hline
\end{tabular}

Table 4. Closing the loops

\begin{tabular}{|c|c|c|c|}
\hline \multirow{3}{*}{$\frac{\text { SLOs }}{\text { Communication skills }}$} & \multicolumn{3}{|c|}{ Excellent+Good } \\
\hline & \multirow{2}{*}{$\frac{2011}{81 \%}$} & \multicolumn{2}{|c|}{$2014 \%$ change } \\
\hline & & $85 \%$ 亿 & $5 \%$ \\
\hline Socially Responsible & $57 \%$ & $80 \%$ & $40 \%$ \\
\hline Global Perspective & $57 \%$ & $75 \%$ ○ & $31 \%$ \\
\hline Quantitative Skills & $52 \%$ & $50 \% ?$ & $-5 \%$ \\
\hline Monitor Financial Perfor & $31 \%$ & $75 \%$ & $142 \%$ \\
\hline Sensitivity to Human Resource & $26 \%$ & $85 \%$ 亿 & $225 \%$ \\
\hline Integrate functional Areas & $31 \%$ & $90 \%$ 全 & $191 \%$ \\
\hline
\end{tabular}




\section{Conclusion}

The AOL process is valuable for learning what areas of improvement are needed to ensure students are learning what we believe they are learning. Using integrated capstone projects as an assessment measure has helped our university identify weak areas and instigate changes that has resulted in marked improvements in student learning. We hve also learned that it is important to let faculty take ownership of AOL and the assessment process should be driven by faculty.

Programs with successful AOL outcomes should begin to share their successes to build unambiguous alternatives for collecting and analyzing AOL data that result in successful program building. While successful student learning is the ultimate goal in higher education program success, renown, and respect are rewarding byproducts that validate and encourage faculty involvement in assessment activities.

\section{References}

Association to Advance Collegiate Schools of Business (AACSB) Accreditation. (2003). Business standards: $\begin{array}{lllll}\text { Approaches } & \text { to } & \text { (n.d.). } & \text { Retrieved from }\end{array}$ http://www.aacsb.edu/en/accreditation/standards/2003-business/aol/aol-approaches.aspx

Association to Advance Collegiate Schools of Business (AACSB). (2013, July). Retrieved from http://accredited.aacsb.edu

Association to Advance Collegiate Schools of Business (AACSB). (2013, May 3). AACSB assurance of learning standards: an interpretation. White Paper No 3. Issued by AACSB International Coordinating Committee and AACSB International Accreditation Quality Committee.

Banta, T. W. (Ed.). (2004). Community college assessment. San Francisco: Jossey-Bass.

Banta, T. W. (Ed.). (2007). Assessing student learning in the disciplines: Assessment update collections. San Francisco: Jossey-Bass.

Banta, T. W. (Ed.). (2011). A bird's-eye view of assessment: Selections from editor's notes. San Francisco: Jossey-Bass.

Christenen, A. L, Judd, A. J., \& Nichols, N. (2010). Implementation of assurance of learning plans: An accounting program and individual course analysis. Journal of Education for Business, 86, 84-91. http://dx.doi.org/10.1080/08832323.2010.480990

Hersh, R. H., \& Keeling, R. P. (2013). Changing institutional culture to promote assessment of higher learning (NILOA Occasional Paper No.17). Urbana, IL: University of Illinois and Indiana University, National Institute for Learning Outcomes Assessment. $\quad$ Retrieved from http://learningoutcomeassessment.org/documents/occasionalpaperseventeen.pdf

LaFleur, E. K., Babin, L. A., \& Lopez, T. B. (2009). Assurance of learning for principles of marketing students: A longitudinal study of a course-embedded direct assessment. Journal of Marketing Education, 31, 131-141. http://dx.doi.org/10.1177/0273475309335242

Maki, P. L. (2010). Assessing for learning: Building a sustainable commitment across the institution (2nd ed.). Sterling, VA: Stylus.

Maki, P. L. (Ed.). (2010). Coming to terms with student outcomes assessment: Faculty and administrators' journeys to integrating assessment in their work and institutional culture. Sterling, VA: Stylus.

Palomba C. A., \& Banta, T. W. (2001). Assessing student competence in accredited disciplines: Pioneering approaches to assessment in higher education (1st ed.). Sterling, VA: Stylus.

Palomba, C.A., \& Banta, T.W. (1999). Assessment essentials: Planning, implementing, and improving assessment in higher education. San Francisco: Jossey-Bass.

Santos, M.R, Aidon, H., \& Douglas, J. (2014). Incorporating multiple-choice questions into an AACSB assurance of learning process: A course-embedded assessment application to an introductory finance course. Journal of Education for Business, 89, 71-76. http://dx.doi.org/10.1080/08832323.2012.757542

Suskie, L. (2009). Assessing student learning: A common sense guide (2nd ed.). San Francisco: Jossey-Bass. 